\title{
Review
}

\section{The Cholinergic Lesion of Alzheimer's Disease: Pivotal Factor or Side Show?}

\author{
Marsel Mesulam \\ Cognitive Neurology and Alzheimer's Disease Center, Northwestern University Feinberg School of Medicine, \\ Chicago, Illinois 60611, USA
}

\begin{abstract}
A profound loss of cortical cholinergic innervation is a nearly invariant feature of advanced Alzheimer's disease (AD). The temporal course of this lesion and its relationship to other aspects of the disease have not yet been fully clarified. Despite assertions to the contrary, a review of the evidence suggests that a perturbation of cholinergic innervation is likely to be present even in the very early stages of $A D$. This cholinergic lesion is unlikely to be a major determinant of the clinical symptoms or of the neuropathological lesions. Nonetheless, it almost certainly contributes to the severity of the cognitive and behavioral deficits, especially in the areas of memory and attention. The cholinergic lesion may also influence the progression of the neuropathological process through complex interactions with amyloidogenesis, $\tau$ phosphorylation and neuroplasticity.
\end{abstract}

\section{Historical Background}

Alzheimer's disease (AD) typically leads to a progressive and incapacitating memory loss accompanied by additional cognitive and behavioral impairments (McKhann et al. 1984). The resultant state of dementia is preceded by a preclinical period of isolated memory loss, also known as mild cognitive impairment or MCI (Petersen et al. 1999). A neuropathological diagnosis of AD is made upon the detection of amyloid plaques and neurofibrillary tangles in limbic and neocortical areas of the brain (Hyman and Trojanowski 1997).

For more than half a century following its introduction into medical nomenclature by Kraeplin (1910), AD tended to be considered a rare and exotic form of dementia. This opinion was altered dramatically in 1976 with the publication of an influential paper by Robert Katzman. In this review, Katzman pointed out that $\mathrm{AD}$ was one of the most common causes of dementia in old age, and the single most likely neuropathological correlate of what had, until then, been known as senility (Katzman 1976). At around the same time, two British teams independently reported that $\mathrm{AD}$ was associated with a severe loss of cholinergic markers in the cerebral cortex (Bowen et al. 1976; Davies and Maloney 1976). These discoveries transformed AD from an obscure entity couched in the arcane nomenclature of plaques and tangles into a disease with a transmitter-based pathophysiology that could be approached in modern neuroscientific terms.

The fact that these developments occurred during the heydays of neurotransmitter research, at a time when the neuroanatomy of central cholinergic pathways was being revealed (Mesulam and Van Hoesen 1976), and soon after the demonstration that cholinergic blockers induced memory impairments (Drachman and Leavitt 1974), turned them into pivotal milestones and triggered a string of related investigations. The severity of dementia in $\mathrm{AD}$ was found to have a positive correlation with the extent of the cholinergic loss (Perry et al. 1981; Francis et al. 1985); the classic neuropathological lesions of $\mathrm{AD}$ such as the senile plaques were attributed to the cholinergic denervation (Arendash et al. 1987); and animals with cholinergic lesions and resultant learning impairments were offered as models of $\mathrm{AD}$ (Bartus et al.

E-MAIL mmesulam@nwu.edu; FAX (312) 908-8789.

Article and publication are at http://www.learnmem.org/cgi/doi/10.1101/ Im.69204.
1982). The opinion was expressed that $\mathrm{AD}$ was a cholinergic disease just as Parkinson's disease was a dopaminergic disease, and that it would soon yield to cholinergic treatments, just as Parkinsonian deficits had yielded to dopaminergic treatments (Coyle et al. 1983).

These developments encouraged the use of cholinergic agents in $\mathrm{AD}$ and culminated in the initial demonstration that inhibitors of acetylcholinesterase could lead to symptomatic improvement (Summers et al. 1986). Medicine seemed headed for another victory on the basis of a linear progression from an understanding of pathophysiology to the rational development of effective treatment. There seemed to be little that was missing in the required chain of events, and the 10-15 yr following the initial discovery of the cholinergic deficit came to be known as the cholinergic era in $\mathrm{AD}$.

But, clouds soon started to gather. First, it became clear that the cholinesterase inhibitors had very modest clinical effects in treating the symptoms of the disease. No patient with dementia became cognitively normal, even after the most vigorous cholinergic therapy. Secondly, the focus of disease-based neuroscience shifted from transmitters to molecular genetics, a development that led to the amyloid cascade hypothesis, according to which the cholinergic denervation was relegated to a secondary role of uncertain significance. Furthermore, despite repeated attempts, the purported effect of cholinergic denervation on the formation of cortical plaques could not be reproduced, so that a major gap emerged between the cholinergic aspect of $\mathrm{AD}$ and its classic neuropathological features such as amyloid plaques, neuronal loss, and neurofibrillary tangles (Thal et al. 1990). Even more devastating challenges came in the form of studies that reported that the cholinergic lesion is not present in early AD (Davis et al. 1999), and that it may not even be as prominent as the loss of other transmitters such as norepinephrine (Zarow et al. 2003). The cholinergic lesion, once celebrated as the prime mover of $\mathrm{AD}$, appeared headed for oblivion.

The purpose of this short review is to revisit selected observations on the nature and course of the cholinergic depletion in $\mathrm{AD}$ and to consider their potential relationship to the neuropathological and cognitive aspects of the disease. The goal is to show that the cholinergic lesion is neither as central as its enthusiasts had once claimed nor as peripheral as some of its detractors would seem to imply. 


\section{A Synopsis of Normal Cholinergic Innervation in the Primate Brain}

The term "cholinergic" is used to designate neural pathways in which acetylcholine (ACh) is released for the purpose of neurotransmission (for review, see M. Mesulam 2004). Cholinergic neurons contain the synthetic enzyme choline acetyltransferase (ChAT). This enzyme and the vesicular ACh transporter are found only in the presynaptic component of cholinergic pathways. The ChAT-containing terminals of cholinergic pathways synapse onto postsynaptic cholinoceptive neurons (Smiley et al. 1997). These postsynaptic components of cholinergic pathways respond to ACh through muscarinic (m1-m5) and several species of nicotinic receptors. The only mode of terminating the synaptic action of ACh is through its catalytic hydrolysis by cholinesterases. Presynaptic, as well as postsynaptic components of cholinergic pathways contain acetylcholinesterase (AChE), whereas the adjacent neuroglia contain butyrylcholinesterase (BChE; Mesulam et al. 2002). Inhibitors of either of these two enzymes exert a cholinomimetic influence by retarding the hydrolysis of ACh.

Muscarinic $\mathrm{m} 1$ receptors are particularly common in the cerebral cortex (Mash et al. 1988). At these receptor sites, the major action of ACh is to induce a prolonged reduction of potassium conductance, so that the cholinoceptive neuron becomes more susceptible to other incoming excitatory inputs (McCormick 1990). This is why ACh is also known as an excitatory neuromodulator of the cerebral cortex.

The primate cerebral cortex does not contain intrinsic cholinergic neurons. The vast majority of its cholinergic innervation originates in the basal forebrain. The hippocampus receives most of its cholinergic input from cholinergic neurons in the medial septal nucleus and the vertical limb of the diagonal band of Broca, whereas the rest of the cerebral cortex and the amygdala receive their cholinergic input from the nucleus basalis of Meynert, the cholinergic cells of which make up the Ch4 cell group (Mesulam et al. 1983a,b; Mesulam and Geula 1988). Nearly 90\% of nucleus basalis neurons are cholinergic, so that this nucleus is also known as the Ch4-nucleus basalis complex. The cholinergic innervation of the striatum is predominantly intrinsic and comes from ChAT-positive striatal interneurons. The cholinergic innervation of the thalamus comes predominantly from the ChATpositive neurons in the pedunculopontine and laterodorsal nuclei of the brainstem, also known as the Ch5 and Ch6 cell groups (Mesulam et al. 1983b). In contrast to primates, the rodent cerebral cortex contains intrinsic cholinergic interneurons, which may supply up to $30 \%$ of the local cholinergic innervation (Levey et al. 1984).

\section{The Nature and Distribution of the Cholinergic Depletion in AD}

A substantial loss of cholinergic innervation in the cerebral cortex is universally accepted as a major aspect of advanced $\mathrm{AD}$ (Geula and Mesulam 1989). This is most severe in the temporal lobes, including the entorhinal cortex, in which up to $80 \%$ of cholinergic axons can be depleted (Geula and Mesulam 1996, 1999). The depletion of cholinergic axons is associated with an equally severe neurofibrillary degeneration and cell loss in the Ch4-nucleus basalis complex (Geula and Mesulam 1999). The cell loss is most severe in the posterior sector of Ch4, in which the neurons that preferentially innervate parts of the temporal lobes are likely to be located (Mesulam and Geula 1988; Geula and Mesulam 1999). In cortical areas depleted of cholinergic input, the $\mathrm{m} 1$ receptors tend to be preserved, whereas the $\mathrm{m} 2$ and nicotinic receptors are reduced (Mash et al. 1985; London et al. 1989). In contrast to the devastation of cholinergic innervation in the cerebral cortex, the cholinergic innervation of the striatum (originating from striatal interneurons) and of the thalamus (originating in the brainstem) remain relatively intact. Therefore, there is no general cholinergic lesion in $\mathrm{AD}$. Rather, there is a selective cholinergic denervation of the cerebral cortex, most severe in the temporal lobes as well as in adjacent limbic and paralimbic areas.

Numerous hypotheses have been advanced to explain the vulnerability of cortical cholinergic innervation in AD (for review, see Geula and Mesulam 1999). Biosynthetic bottlenecks in the production of $\mathrm{ACh}$, special vulnerabilities to amyloid, and impairments of axonal transport have been invoked as possible explanations, but proof is lacking. The answer may lie in the anatomical identity of the Ch4-nucleus basalis complex. This cell group, together with the hippocampus, amygdala, and entorhinal cortex, is part of an uninterrupted band of core limbic areas (Mesulam 2000a,b). These are the regions of the brain that attract the greatest neurofibrillary degeneration and related cell death in the course of aging and AD (Mesulam 1999). The severe and selective loss of cortical cholinergic innervation may thus reflect the anatomical position and connectivity of the nucleus basalis rather than any special property of cholinergic neurotransmission or biosynthesis.

\section{Is the Cholinergic Depletion a Late or Early Event in $\mathrm{AD}$ ?}

The initial reports of cortical cholinergic denervation and of cell loss in the nucleus basalis were based on patients who had advanced disease (Whitehouse et al. 1981; Geula and Mesulam 1989). Nonetheless, the implicit assumption during the cholinergic era was that these transmitter-specific events occurred early in the course of the disease, perhaps as initiating events. Two sets of observations seemed to corroborate this impression. In one of these, Perry and colleagues reported that the cholinergic denervation of the temporal lobe was present even in patients at the early stages of AD neuropathology (Perry et al. 1981). In another landmark study, Bowen and colleagues obtained biopsy specimens from patients with presenile dementia and found a significant loss of ChAT activity even within one year of symptom onset in patients with a diagnosis of $\mathrm{AD}$, but not in those with other diagnoses (Bowen et al. 1982).

However, three subsequent reports, all based on elderly subjects, have challenged the assumption that the cholinergic depletion is an early event in AD. Two of these studies report that mild $\mathrm{AD}$ is not associated with a loss of cortical ChAT (Davis et al. 1999; DeKosky et al. 2002), whereas the third suggests that the number of cholinergic Ch4 neurons may not be decreased in early AD (Gilmor et al. 1999). These carefully executed studies imply that the cortical cholinergic depletion may be a terminal and perhaps subsidiary event, especially in late-onset (i.e., senile) $\mathrm{AD}$, seriously questioning the current practice of using cholinomimetic agents in mild or preclinical stages of the disease.

However, there are a number of reasons for re-evaluating these implications. First, ChAT is neither the rate-limiting enzyme for ACh synthesis nor a particularly effective marker of cholinergic neurotransmission. Conceivably, a partial loss of cholinergic synapses in the cerebral cortex could trigger a compensatory up-regulation of ChAT within adjacent cholinergic axons without inducing a replacement of the lost cholinergic synapses. Moreover, because ChAT is measured in terms of enzyme activity per weight of protein, cortical atrophy could alter the denominator in this calculation in a way that would obscure a net decline of ChAT in a cortical area that had undergone atrophy. It is also necessary to consider the possibility that cell number is not necessarily a sensitive measure of Ch4-nucleus

\section{Learning \& Memory}

www.learnmem.org 
basalis integrity, and that the earliest age- and AD-related changes in this structure may take the form of neurofibrillary degeneration and a loss of cell volume (Mesulam et al. 1987; Sassin et al. 2000). More direct, although more laborious, approaches for assessing the state of cholinergic neurotransmission might involve light microscopic morphometry to quantitate the density of cholinergic axons (Geula and Mesulam 1989) and binding assays for the vesicular acetylcholine transporter to quantitate cholinergic terminals (Efange et al. 1997).

Beyond these caveats related to methodology, observations on the aging brain provide additional reasons for suspecting that a depletion of cortical cholinergic denervation is an early feature of late-life AD. For example, Ch4 neurons (but not the striatal or brainstem cholinergic neurons) are among the most sensitive cells in the whole brain to age-related neurofibrillary degeneration, so that neurofibrillary tangles in the Ch4-nucleus basalis complex are commonly detected in cognitively normal elderly subjects as well as in those who enter the stages of MCI and mild AD (Mesulam 2000a; Sassin et al. 2000). This age-related neurofibrillary degeneration is likely to disrupt cortical cholinergic innervation even before the death of Ch4-nucleus basalis neurons (Mesulam 2000a). In fact, nondemented elderly individuals with no apparent change of cell counts in the nucleus basalis can display an age-related modest, but significant decrement of cortical cholinergic innervation, especially in the temporal lobes, as shown by postmortem counts of cholinergic axons and vesicular acetylcholine transporter sites and by in vivo mappings of cholinergic terminals (Geula and Mesulam 1989; Emre et al. 1993; Kuhl et al. 1996; Efange et al. 1997). The existence of this agerelated change may help to explain why the cholinergic loss in the initial stages of the disease is more difficult to detect in senile than presenile $\mathrm{AD}$; the former group would have an age-matched comparison group in which a loss of cholinergic innervation is already in progress, so that the magnitude of the observed differences would be less conspicuous.

In summary, there is universal agreement that a severe loss of cortical cholinergic innervation is part of advanced $\mathrm{AD}$, senile as well as presenile. There is also at least one set of unchallenged data showing that a similar cholinergic lesion exists in the initial stages of presenile AD (Bowen et al. 1982). The presence of cholinergic denervation in the initial stages of senile $\mathrm{AD}$, however, has been challenged. The comments above suggest that this challenge should be evaluated in the light of what is known about age-related changes in cortical cholinergic pathways. The existence of such changes indicates that the very initial neuropathology of late-onset (senile) AD unfolds upon a basal state of agerelated cholinergic denervation. What has not yet been determined is whether the clinical onset of mild $\mathrm{AD}$ (or the preclinical state known as MCI) is temporally linked to a further decrement of cholinergic transmission beyond what happens on the basis of age alone, or whether these clinical milestones represent interactions of the pre-existing cholinergic loss with the additional processes of amyloidogenesis, neurofibrillary degeneration, and synaptic loss.

The specificity of the cholinergic lesion in $\mathrm{AD}$ is more difficult to address. Alzheimer's disease is associated with substantial variability in the involvement of noncholinergic cortical transmitters, especially the monoamines (Geula and Mesulam 1999). A review of the literature suggests that the cholinergic loss is more consistent than the loss of other transmitters, and that a selective loss of cholinergic transmission is not unusual, whereas a selective loss of one of the monoamines in the absence of cholinergic denervation is exceedingly rare (Perry et al. 1981; Minger et al. 2000). These generalizations, however, apply mostly to advanced disease and need to be re-evaluated at the early stages of the dementia.

\section{Cholinergic Therapies and Relationship of Dementia to Cholinergic Loss}

Circumstantial evidence for the relevance of the cholinergic lesion to the clinical features of the dementia comes from pharmacological studies showing that cholinomimetics induce symptomatic improvement in both mild and advanced dementia, in senile as well as presenile forms of $\mathrm{AD}$, and that there is a reasonable correlation between the magnitude of cholinergic depletion and the severity of the dementia (Baskin et al. 1999; Minger et al. 2000; Pappas et al. 2000; Doody et al. 2001).

The cholinergic depletion of $\mathrm{AD}$ displays relatively uniform patterns of distribution. In general, areas within the temporal lobes display the most marked depletion, whereas primary sensory-motor areas and the cingulate gyrus display the least (Geula and Mesulam 1996). The hippocampus and entorhinal cortex are among the most severely affected areas, a relationship that may account, at least in part, for the characteristic severity of the memory loss in AD (Pappas et al. 2000). There is also some evidence for anatomical clinico-pathological relationships suggesting that abnormalities in attentional processes may be correlated with the extent of cholinergic depletion in medial prefrontal cortex, whereas abnormalities in graphomotor functions may be correlated with the cholinergic depletion in the inferior parietal cortex (Pappas et al. 2000).

There is no single aspect of the dementia that seems to respond best or most consistently to cholinergic therapy, probably because the cholinergic depletion is multifocal and arises on a background of other pathological changes. The exact impact of the cholinergic lesion upon the individual clinical and neuropathological features of AD remains mostly conjectural. To explore the nature of these conjectures, it is necessary to review some of the functions that have been attributed to cortical cholinergic pathways in the normal brain.

\section{Behavioral Neuroanatomy of Cortical Cholinergic Innervation}

Cholinergic axons originating in the Ch4-nucleus basalis complex innervate all parts of the cerebral cortex, including limbic structures such as the hippocampus, entorhinal cortex, and amygdala (Mesulam et al. 1992; Mesulam and Geula 1993). This innervation is most intense within the limbic system, intermediate within association cortices, and least intense within primary sensory areas. The functional affiliation with the limbic system is further highlighted by the fact that the Ch4-nucleus basalis complex receives its cortical input almost exclusively from limbic areas, although it sends projections to all parts of the cerebral cortex, limbic as well as nonlimbic (Mesulam and Mufson 1984). The Ch4-nucleus basalis complex is thus in a position to act as a cholinergic relay for modulating the function of all cortical areas in a way that is predominantly responsive to the state of the limbic system.

The nucleus basalis also receives inputs from serotonergic, dopaminergic, and noradrenergic nuclei of the brainstem (Smiley and Mesulam 1999). Its neurons have widespread outputs, heterogeneous inputs, and overlapping dendritic fields that dip into passing fiber tracts. These features have led to the characterization of the nucleus basalis as a telencephalic extention of the brainstem reticular formation (Ramon-Moliner and Nauta 1966). From the vantage point of behavioral neuroanatomy, therefore, the nucleus basalis sits at the confluence of the mediobasal limbic system and the rostral reticular formation.

Because cholinergic pathways innervate all cortical areas, they can potentially influence all aspects of cognition and behavior. However, the physiological pattern of excitatory neuromodulation, the affiliations with the ascending reticular activat- 
ing system, and the preferential interactions with limbic areas also suggest that neocortical cholinergic pathways are particularly critical for the modulation of attention (i.e., the on-line holding and dynamic enhancement of neural responses to salient events) and memory (i.e., the off-line encoding, retention, and retrieval of past events and contingencies). The relationship to attention is likely to reflect the widespread distribution of cortical cholinergic innervation and the neuromodulatory role of ACh, whereas the relationship to memory may additionally reflect the high concentration of cholinergic innervation within the hippocampus, entorhinal cortex, and amygdala.

\section{Memory and Cortical Cholinergic Innervation}

Human subjects respond to the muscarinic antagonist scopolamine with a memory impairment somewhat similar to that seen in AD (Drachman and Leavitt 1974). This clinical observation and the characteristically intense cholinergic innervation of limbic areas, including the hippocampus, have helped to generate the opinion that cortical cholinergic neurotransmission plays a crucial role in memory function. The exact nature of this relationship, however, continues to elude a clear description. In rodents, the selective immunolesioning of cholinergic neurons in the basal forebrain causes learning and memory impairments in some experiments, but not in all (Berger-Sweeney et al. 1994; Wenk et al. 1994; Galani et al. 2002). In primates, even nonselective destructive lesions that include the cholinergic as well as noncholinergic components of the nucleus basalis have lead to memory deficits in some experiments (Ridley et al. 1986), but not in others (Voytko et al. 1994). Even in experiments in which learning deficits emerge after cholinergic denervation, the deficits have been attributed to attentional rather than mnemonic factors (Everitt and Robbins 1997; Sarter and Bruno 2000). There is somewhat more consistent evidence that the cholinergic pathway from the nucleus basalis to the amygdala may enhance memory consolidation, especially of affectively salient events (McGaugh et al. 1993; Everitt and Robbins 1997; Power et al. 2002). Furthermore, during Pavlovian conditioning, approximately half of the nucleus basalis neurons show a significantly greater change of activity in response to a tone that predicts the occurrence of a mildly aversive unconditioned stimulus than to a tone that does not (Whalen et al. 1994).

The role of acetylcholine in hippocampal long-term potentiation (Tanaka et al. 1989; Auerbach and Segal 1994) may provide one of several cellular mechanisms that underlies the putative relationship of cholinergic pathways to memory. In another line of investigation, brain slice experiments in piriform cortex of the rat have shown that acetylcholine can selectively suppress intrinsic synaptic transmission through a presynaptic mechanism, while leaving extrinsic afferent input unaffected. This selective suppression could prevent interference from previously stored patterns during the learning of new relationships (Hasselmo 1992). Buzsáki (1989) has proposed a different model, according to which the cholinergic innervation, especially of the hippocampal complex, plays a major role in switching from online attentive processing, characterized by the hippocampal theta rhythm, to off-line memory consolidation, characterized by sharp wave activity.

Even if the importance of cortical cholinergic innervation to memory were to be established more definitively, however, cholinergic depletion could not be the only (or even major) cause of the memory loss, as $\mathrm{AD}$ is also characterized by prominent neurofibrillary degeneration, cell loss, and $\beta$ amyloid accumulation in areas that are critical to memory, including the entorhinal region, amygdala, hippocampus, and prefrontal cortex.

\section{Attentional State and Cortical Cholinergic Innervation}

The extent to which cortical cholinergic innervation influences memory has not been resolved. In contrast, there is considerable agreement concerning the importance of this pathway to various aspects of attention, including the setting of signal-to-noise ratios during information processing and the on-line holding of information (Voytko et al. 1994; Dias et al. 1996; Everitt and Robbins 1997; Sarter and Bruno 2000; Himmelheber et al. 2001; Galani et al. 2002). The electrophysiological correlates of these behavioral relationships are being explored. Potentially relevant experiments show that stimulation of the nucleus basalis elicits cortical EEG activation via muscarinic receptors and that it triggers a change in subthreshold membrane potential fluctuations from large amplitude slow oscillations to low amplitude fast (20$40 \mathrm{~Hz}$ ) oscillations (Metherate et al. 1992). Inactivation of the nucleus basalis, on the other hand, suppresses low-voltage fast EEG activity in the cerebral cortex (Dringenberg and Vanderwolf 1996).

The anatomical organization of cortical cholinergic pathways is consistent with a prominent role in attentional processes. As noted above, the nucleus basalis projects to all cortical areas, while receiving its cortical inputs only from components of the limbic system, an arrangement through which it can selectively enhance the release of cortical ACh in response to events that are of limbic relevance. Cortical cholinergic innervation is thus in a position to preferentially promote the cortical impact of events that are of emotional and motivational significance. In keeping with this formulation, neurons of the nucleus basalis in the monkey are selectively sensitive to novel and motivationally relevant sensory events (DeLong 1971; Wilson and Rolls 1990), and the novelty-related P300 potential in the human cerebral cortex is abolished upon the administration of cholinergic blockers (Hammond et al. 1987). Impairments of complex attentional functions, including novelty-seeking behaviors, are common in AD (Daffner et al. 1992; Price et al. 1993). These aspects of the dementia are occasionally as prominent as the memory impairments and could reflect, at least in part, consequences of the cholinergic lesion.

\section{Cortical Acetylcholine and Plasticity}

Neuroplasticity is a life-long process that mediates the structural and functional reaction of dendrites, axons, and synapses to experience, attrition, and injury. One of the most interesting functional correlates of cortical ACh is its role in mediating neuroplasticity (Bear and Singer 1986). The selective lesioning of cortical cholinergic innervation in the rat was shown to interfere with experience-dependent plasticity in the barrel fields. In one experiment, all whiskers except for D2 and D3 were trimmed. This led to a pairing between the D2 and D3 barrel fields in the cerebral cortex, so that the D2 neurons started to show a greater responsivity to stimulation of D3 than to stimulation of the adjacent D1, which had been trimmed. This pairing, indicative of experience-induced synaptic plasticity, could not be obtained in rats with selective immunotoxic lesions of the cholinergic neurons in the nucleus basalis (Baskerville et al. 1997). In another experiment on newborn rat pups, barrels representing intact whiskers failed to show the expected expansion into the territory of barrels representing trimmed whiskers in animals with nucleus basalis lesions (Zhu and Waite 1998). Furthermore, pairing auditory stimuli with the electrical stimulation of the nucleus basalis in adult rats caused a long-lasting reorganization of primary auditory cortex, so that the area optimally responsive to the paired tone expanded substantially. This plasticity was not observed following the selective immunotoxic destruction of cholinergic nucleus basalis neurons (Kilgard and Merzenich 1998). On the

\section{Learning \& Memory \\ www.learnmem.org}


basis of these observations, it appears that cortical cholinergic denervation can undermine the learning-dependent reorganization of cortical representations and perhaps also the ability of the brain to keep itself in good repair in response to attrition and injury (Mesulam 1999; Conner et al. 2003). These aspects of cholinergic denervation would be expected to have two major consequences for $\mathrm{AD}$; they would further exacerbate the memory impairment and they would accelerate the transition from normal aging to AD (Mesulam 1999).

\section{Cholinergic Depletion and Its Influence on Plaques and Tangles}

There is currently little support for the hypothesis that amyloid plaques or neurofibrillary tangles are caused by the loss of cholinergic innervation. Nonetheless, complex interactions of potentially profound pathophysiological significance are being identified between cholinergic neurotransmission and amyloidogenesis as well as $\tau$ phosphorylation. In transfected PC12 cells, for example, the stimulation of the $\mathrm{m} 1$ muscarinic receptor decreases $\tau$ phosphorylation (Sadot et al. 1996). This relationship implies that a cholinergic depletion could induce $\tau$ hyperphosphorylation, a process of fundamental importance to the formation of neurofibrillary tangles. Furthermore, m1- and m3mediated muscarinic stimulation of cortical neurons has been shown to promote the processing of amyloid precursor protein (APP) by the $\alpha$ secretase pathway (Nitsch et al. 1992). This pathway splits APP in the middle of the $\beta$ amyloid domain, and therefore precludes the subsequent release of the potentially neurotoxic $\beta$ amyloid. Additional in vitro experiments have shown that nicotine-mediated cholinergic neurotransmission may protect neurons from $\beta$ amyloid neurotoxicity (Kihara et al. 1997). These experiments imply that a cholinergic depletion may not only increase the production of $\beta$ amyloid, but also its local neurotoxic effects. Numerous experiments have also shown that $\beta$ amyloid disrupts ACh synthesis and the signal-transduction events associated with cholinergic neurotransmission (Kelly et al. 1996; Auld et al. 1998). It appears, therefore, that AD may be associated with a vicious cycle whereby the cholinergic depletion intensifies both the production and neurotoxicity of $\beta$ amyloid, which, in turn, further increases the cholinergic deficit and consequently, the phosphorylation of $\tau$. The significance of these theoretical considerations to the clinical and neuropathological course of $\mathrm{AD}$ remains to be demonstrated. A potentially relevant study shows that the density of amyloid plaques and neurofibrillary tangles in Parkinson's disease is positively correlated with the exposure to anticholinergic drugs, suggesting that an interference with cholinergic neurotransmission may actually promote these neuropathological events (Perry et al. 2003).

\section{Conclusions}

Aging is the single most important risk factor for AD. Aging is also associated with the emergence of neurofibrillary degeneration in the Ch4-nucleus basalis complex and a corresponding loss of cholinergic innervation in the cerebral cortex. A state of cholinergic denervation is therefore an intrinsic part of the preclinical and mild stages of AD arising in old age. The cholinergic depletion of very mild $\mathrm{AD}$ is more easily demonstrated in younger (presenile) patient groups, in which cholinergic markers are being compared with those of young control subjects with intact cholinergic pathways. In the older patients, any further cholinergic depletion occurs on a background of age-related changes and may therefore be more difficult to detect.

By the time $\mathrm{AD}$ reaches an advanced stage, extensive neurofibrillary degeneration and neuronal death have already spread throughout the Ch4-nucleus basalis complex, and a dramatic loss of cholinergic innervation has become established in many parts of the cerebral cortex. The magnitude of this cholinergic loss tends to be correlated with the severity of the dementia. There is also preliminary evidence that impairments in different cognitive domains are selectively correlated with the severity of the cholinergic depletion in parts of the cerebral cortex that are specialized for that function (Pappas et al. 2000).

Cholinergic axons innervate all cortical areas, so that the cholinergic depletion of $\mathrm{AD}$ is likely to contribute to all of the associated cognitive and behavioral impairments. However, the behavioral anatomy of cholinergic pathways also suggests that this denervation is likely to have its greatest clinical impact on the integrity of attention and memory. The putative influence of cholinergic pathways on neuroplasticity, amyloid processing, and $\tau$ phosphorylation introduces additional features that may link the cholinergic lesion to disease progression.

The cholinergic loss is neither a primary pathogenetic factor of $\mathrm{AD}$ nor the principal correlate of its clinical manifestations. The emergence of cholinergic depletion in natural aging and its prominence in established $\mathrm{AD}$ can be attributed to the location of the nucleus basalis within the limbic system and the uniquely high susceptibility of limbic neurons to neurofibrillary cytopathology in the course of events that lead to AD. As the cholinergic depletion becomes established, it undoubtedly influences the nature of the cognitive deficits and perhaps even the progression of the other neuropathological lesions. These considerations are consistent with the current view that cholinergic therapies are unlikely to offer definitive treatments for AD. Nonetheless, they are likely to remain major components of a concerted approach aiming to influence the onset and progression of $\mathrm{AD}$ from as many directions as possible.

\section{ACKNOWLEDGMENTS}

Supported by an Alzheimer's Disease Center grant from the NIA (AG-13854).

\section{REFERENCES}

Arendash, G.W., Millard, W.J., Dunn, A.J., and Meyer, E.M. 1987. Long-term neuropathological and neurochemical effects of nucleus basalis lesions in the rat. Science 238: 952-956.

Auerbach, J.M. and Segal, M. 1994. A novel cholinergic induction of long-term potentiation in rat hippocampus. J. Neurophysiol. 72: 2034-2040.

Auld, D.S., Kar, S., and Quirion, R. 1998. $\beta$-Amyloid peptides as direct cholinergic neuromodulators: A missing link? Trends Neurosci. 21: $43-49$.

Bartus, R.T., Dean, R.L., Beer, B., and Lippa, A.D. 1982. The cholinergic hypothesis of geriatric memory dysfunction. Science 21 7: 408-417.

Baskerville, K.A., Schweitzer, J.B., and Herron, P. 1997. Effects of cholinergic depletion on experience-dependent plasticity in the cortex of the rat. Neuroscience 80: 1159-1169.

Baskin, D.S., Browning, J.L., Pirozzolo, F.J., Korporaal, S., Baskin, J.A., and Appel, S.A. 1999. Brain choline acetyltransferase and mental function in Alzheimer disease. Arch. Neurol. 56: 1121-1123.

Bear, M.F. and Singer, W. 1986. Modulation of visual cortical plasticity by acetylcholine and noradrenaline. Nature 320: 172-176.

Berger-Sweeney, J., Heckers, S., Mesulam, M.M., Wiley, R.G., Lappi, D.A., and Sharma, M. 1994. Differential effects upon spatial navigation of immunotoxin-induced cholinergic lesions of the medial septal area and nucleus basalis magnocellularis. J. Neurosci. 14: 4507-4519.

Bowen, D.M., Smith, C.B., White, P., and Davison, A.N. 1976. Neurotransmitter-related enzymes and indices of hypoxia in senile dementia and other abiotrophies. Brain 99: 459-496.

Bowen, D.M., Benton, J.S., Spillane, J.A., Smith, C.C.T., and Allen, S.J. 1982. Choline acetyltransferase activity and histopathology of frontal neocortex from biopsies of demented patients. J. Neurol. Sci. 57: 191-202.

Buszáki, G. 1989. Commentary: Two-stage model of memory trace formation: A role for "noisy" brain states. Neuroscience 31: 551-570.

Conner, J.M., Culberson, A., Packowski, C., Chiba, A.A., and Tuszynski, M.H. 2003. Lesions of the basal forebrain cholinergic system impair 
task acquisition and abolish cortical plasticity associated with motor skill learning. Neuron 38: 819-829.

Coyle, J.T., Price, D.L., and DeLong, M.R. 1983. Alzheimer's disease: A disorder of cortical cholinergic innervation. Science 219: 1184-1190.

Daffner, K.R., Scinto, L.F., Weintraub, S., Guinessey, J.E., and Mesulam, M.M. 1992. Diminished curiosity in patients with probable Alzheimer's disease as measured by exploratory eye movements. Neurology 42: 320-328.

Davies, P. and Maloney, A.J.F. 1976. Selective loss of central cholinergic neurons in Alzheimer's disease. Lancet 2: 1943.

Davis, K.L., Mohs, R.C., Marin, D., Purohit, D.P., Perl, D.P., Lantz, M., Austin, G., and Haroutunian, V. 1999. Cholinergic markers in elderly patients with early signs of Alzheimer's disease. J. Am. Med. Assoc. 281: 1401-1406.

DeKosky, S.T., Ikonomovic, M.D., Styren, S.D., Beckett, L., Wisniewski, S., Bennett, D.A., Cochran, E.J., Kordower, J.H., and Mufson, E.J. 2002. Upregulation of choline acetyltransferase activity in hippocampus and frontal cortex of elderly subjects with mild cognitive impairment. Ann. Neurol. 51: 145-155.

DeLong, M.R. 1971. Activity of pallidal neurons during movement. J. Neurophysiol. 34: 414-427.

Dias, E.C., Compaan, D.M., Mesulam, M.M., and Segraves, M.A. 1996. Selective disruption of memory-guided saccades with injecton of a cholinergic antagonist in the frontal eye field of monkey. Soc. Neurosci. Abst. 22: 418.

Doody, R.S., Stevens, J.C., Beck, C., Dubinsky, R.M., Kaye, J.A., Gwyther, L., Mohs, R.C., Thal, L.J., Whitehouse, P.J., DeKosky, S.T., et al. 2001. Practice parameter: Management of dementia (an evidence-based review). Report of the quality standards subcommittee of the American Academy of Neurology. Neurology 56: $1154-1166$.

Drachman, D.A. and Leavitt, J. 1974. Human memory and the cholinergic system-A relationship to aging? Arch. Neurol. 30: $113-121$.

Dringenberg, H.C. and Vanderwolf, C.H. 1996. Cholinergic activation of the electrocorticogram: An amygdaloid activating system. Exper. Brain Res. 108: 285-296.

Efange, S.M.N., Garland, E.M., Staley, J.K., Khare, A.B., and Mash, D.C. 1997. Vesicular acetylcholine transporter density and Alzheimer's disease. Neurobiol. Aging 18: 407-413.

Emre, M., Heckers, S., Mash, D.C., Geula, C., and Mesulam, M.M. 1993 Cholinergic innervation of the amygdaloid complex in the human brain and its alterations in old age and Alzheimer's disease. J. Comp. Neurol. 336: 117-134.

Everitt, B.J. and Robbins, T.W. 1997. Central cholinergic systems and cognition. Annu. Rev. Psychol. 48: 649-684.

Francis, P.T., Palmer, A.M., Sims, N.R., Bowen, D.M., Davison, A.N. Esiri, M.M., Neary, D., Snowden, J.S., and Wilcock, G.K. 1985 Neurochemical studies of early-onset Alzheimer's disease. Possible influence on treatment. New Eng. J. Med. 313: 7-11.

Galani, R., Lehmann, O., Bolmont, T., Aloy, E., Bertrand, F., Lazarus, C., Jeltsch, H., and Cassel, J.C. 2002. Selective immunolesions of CH4 cholinergic neurons do not disrupt spatial memory in rats. Physiol. Behav. 76: 75-90.

Geula, C. and Mesulam, M.M. 1989. Cortical cholinergic fibers in aging and Alzheimer's disease: A morphometric study. Neuroscience 33: $469-481$.

. 1996. Systematic regional variations in the loss of cortical cholinergic fibers in Alzheimer's disease. Cerebral Cortex 6: 165-177.

- 1999. Cholinergic systems in Alzheimer's disease. In Alzheimer disease, 2nd Ed. (eds. R.D. Terry et al.), pp. 69-292. Lippincott, Williams \& Wilkins, Philadelphia, PA.

Gilmor, M.L., Erickson, J.D., Varoqui, H., Hersh, L.B., Bennett, D.A., Cochran, E.J., Mufson, E.J, and Levey, A.I. 1999. Preservation of nucleus basalis neurons containing choline acetyltransferase and the vesicular acetylcholine transporter in the elderly with mild cognitive impairment and early Alzheimer's disease. J. Comp. Neurol. 411: $693-704$

Hammond, E.J., Meador, K.J., Aunq-Din, R., and Wilder, B.J. 1987. Cholinergic modulation of human P3 event-related potentials. Neurology 37: 346-350.

Hasselmo, M.E. 1992. Cholinergic modulation of cortical associative memory function. J. Neurophysiol. 67: 1230-1246.

Himmelheber, A.M., Sarter, M., and Bruno, J.P. 2001. The effects of manipulations of attentional demand on cortical acetylcholine release. Cog. Brain Res. 12: 353-370.

Hyman, B.T. and Trojanowski, J.Q. 1997. Editorial on consensus recommendations for the postmortem diagnosis of Alzheimer's disease from the National Institute on Aging and the Reagan Institute Working Group on Diagnostic Criteria for the Neuropathological Assessment of Alzheimer's Disease. J. Neuropathol. Exper. Neurol. 56: 1095-1097.
Katzman, R. 1976. The prevalence and malignancy of Alzheimer disease. Arch. Neurol. 33: 217-218.

Kelly, J.F., Furukawa, K., Barger, S.W., Rengen, M.R., Mark, R.J., Blanc, E.M., Roth, G.S., and Mattson, M.P. 1996. Amyloid $\beta$-peptide disrupts carbachol-induced muscarinic cholinergic signal transduction in cortical neurons. Proc. Natl. Acad. Sci. 93: 6753-6758.

Kihara, T., Shimohama, S., Sawaa, H., Kimura, J., Kume, T., Kochiyama, H., Maeda, T., and Akaike, A. 1997. Nicotinic receptor stimulation protects neurons against $\beta$-amyloid toxicity. Ann. Neurol. 42: $159-163$.

Kilgard, M.P. and Merzenich, M.M. 1998. Cortical map reorganization enabled by nucleus basalis activity. Science 279: 1714-1718.

Kraepelin, E. 1910. Lehrbuch der Psychiatrie. Leipzig, Barth.

Kuhl, D.E., Minoshima, S., Fessler, J.A., Frey, K.A., Foster, N.L., Ficaro, E.P., Wieland, D.M., and Koeppe, R.A. 1996. In vivo mapping of cholinergic terminals in normal aging, Alzheimer's disease, and Parkinson's disease. Ann. Neurol. 40: 399-410.

Levey, A.I., Wainer, B.H., Rye, D.B., Mufson, E.J., and Mesulam, M.M. 1984. Choline acetyltransferase-immunoreactive neurons intrinsic to rodent cortex and distinction from acetylcholinesterase-positive neurons. Neuroscience 13: 341-353.

London, E.D., Ball, M.J., and Waller, S.B. 1989. Nicotinic binding sites in cerebral cortex and hippocampus in Alzheimer's dementia. Neurochem. Res. 14: 745-750.

Mash, D.C., Flynn, D.D., and Potter, L.T. 1985. Loss of M2 muscarine receptors in the cerebral cortex in Alzheimer's disease and experimental cholinergic denervation. Science 228: 115-117.

Mash, D.C., White, W.F., and Mesulam, M.M. 1988. Distribution of muscarinic receptor subtypes within architectonic subregions of the primate cerebral cortex. J. Comp. Neurol. 278: 265-274.

McCormick, D.A. 1990. Cellular mechanisms of cholinergic control of neocortical and thalamic neuronal excitability. In Brain cholinergic systems (eds. M. Steriade and D. Biesold), pp. 236-264. Oxford University Press, Oxford, UK.

McGaugh, J.L., Introini-Collison, I.B., Cahill, L.F., Castellano, C., Dalmaz, C., Parent, M.B., and Williams, C.L. 1993. Neuromodulatory systems and memory storage: Role of the amygdala. Behav. Brain Res. 58: 81-90.

McKhann, G., Drachman, D.A., Folstein, M., Katzman, R., Price, D., and Stadlan, E.M. 1984. Clinical diagnosis of Alzheimer's disease. Neurology 34: 939-944.

Mesulam, M.M. 1999. Neuroplasticity failure in Alzheimer's disease: Bridging the gap between plaques and tangles. Neuron 24: 521-529. . 2000a. Aging, Alzheimer's disease, and dementia: Clinical and neurobiological perspectives. In Principles of behavioral and cognitive neurology (ed. M.M. Mesulam), pp. 439-522. Oxford University Press, New York

- 2000b. Behavioral neuroanatomy: Large-scale networks, association cortex, frontal syndromes, the limbic system and hemispheric specialization. I Principles of behavioral and cognitive neurology (ed. M.M. Mesulam), pp. 1-120. Oxford University Press, New York.

. 2004. The cholinergic innervation of the human cerebral cortex. Prog. Brain Res. (in press).

Mesulam, M.M. and Geula, C. 1988. Nucleus basalis (Ch4) and cortical cholinergic innervation in the human brain: Observations based on the distribution of acetylcholinesterase and choline acetyltransferase. J. Comp. Neurol. 275: 216-240.

. 1993. Chemoarchitectonics of axonal and perikaryal acetylcholinesterase along information processing systems of the human cerebral cortex. Brain Res. Bull. 33: 137-153.

Mesulam, M.M. and Mufson, E.J. 1984. Neural inputs into the nucleus basalis of the substantia innominata (Ch4) in the rhesus monkey. Brain 107: 253-274.

Mesulam, M.M. and Van Hoesen, G.W. 1976. Acetylcholinesterase-rich projections from the basal forebrain of the rhesus monkey to neocortex. Brain Res. 109: 152-157.

Mesulam, M.M., Mufson, E.J., Levey, A.I., and Wainer, B.H. 1983a. Cholinergic innervation of cortex by the basal forebrain: Cytochemistry and cortical connections of the septal area, diagonal band nuclei, nucleus basalis (substantia innominata), and hypothalamus in the rhesus monkey. J. Comp. Neurol. 214: 170-197.

Mesulam, M.M., Mufson, E.J., Wainer, B.H., and Levey, A.I. 1983b. Central cholinergic pathways in the rat: An overview based on an alternative nomenclature (Ch1-Ch6). Neuroscience 10: 1185-1201.

Mesulam, M.M., Mufson, E.J., and Rogers, J. 1987. Age-related shrinkage of cortically projecting cholinergic neurons: A selective effect. Ann. Neurol. 22: 31-36.

Mesulam, M.M., Hersh, L.B., Mash, D.C., and Geula, C. 1992. Differential cholinergic innervation within functional subdivisions of the human cerebral cortex: A choline acetyltransferase study. J.

\section{Learning \& Memory}


Comp. Neurol. 318: 316-328.

Mesulam, M.M., Guillozet, A., Shaw, P., Levey, A., Duysen, E.G., and Lockridge, O. 2002. Acetylcholinesterase knockouts establish central cholinergic pathways and can use butyrylcholinesterase to hydrolyze acetylcholine. Neuroscience 110: 627-639.

Metherate, R., Cox, C.L. and Ashe, J.H. 1992. Cellular bases of neocortical activation: Modulation of neuronal oscillations by the nucleus basalis and endogenous acetylcholine. J. Neurosci. 12: 4701-4711.

Minger, S.L., Esiri, M.M., McDonald, B., Keene, J., Carter, J., Hope, T. and Francis, P.T. 2000. Cholinergic deficits contribute to behavioral disturbance in patients with dementia. Neurology 55: 1460-1467.

Nitsch, R.M., Slack, B.E., Wurtman, R.J., and Growdon, J.H. 1992 Release of Alzheimer amyloid precursor derivatives stimulated by activation of muscarinic acetylcholine receptors. Science 258: 304-307.

Pappas, B.A., Bayley, P.J., Bui, B.K., Hansen, L.A., and Thal, L. 2000. Choline acetyltransferase activity and cognitive domain scores of Alzheimer's patients. Neurobiol. Aging 21: 11-17.

Perry, E.K., Blessed, G., Tomlinson, B.E., Perry, R.H., Crow, T.J., Cross, A.J., Dockray, G.J., Dimaline, R., and Arregui, A. 1981. Neurochemical activities in human temporal lobe related to aging and Alzheimer-type changes. Neurobiol. Aging 2: 251-256.

Perry, E.K., Kilford, L., Lees, A.J., Burn, D.J., and Perry, R.H. 2003. Increased Alzheimer pathology in Parkinson's disease related to antimuscarinic drugs. Ann. Neurol. 54: 235-238.

Petersen, R.C., Smith, G.E., Waring, S.C., Ivnik, R.J., Tangalos, E.G., and Kokmen, E. 1999. Mild cognitive impairment. Clinical characterization and outcome. Arch. Neurol. 56: 303-308.

Power, A.E., Thal, L.J., and McGaugh, J.L. 2002. Lesions of the nucleus basalis magnocellularis induced by 192 IgG-saporin block memory enhancement with posttraining norepinephrine in the basolateral amygdala. Proc. Natl. Acad. Sci. 99: 2315-2319.

Price, B.H., Gurvit, H., Weintraub, S., Geula, C., Leimkuhler, E., and Mesulam, M. 1993. Neuropsychological patterns and language deficits in 20 consecutive cases of autopsy-confirmed Alzheimer's disease. Arch. Neurol. 50: 931-937.

Ramon-Moliner, E. and Nauta, W.J.H. 1966. The isodendritic core of the brain. J. Comp. Neurol. 126: 311-336.

Ridley, R.M., Murray, T.K., Johnson, J.A., and Baker, H.F. 1986. Learning impairment following lesion of the basal nucleus of Meynert in the marmoset: Modification by cholinergic drugs. Brain Res. 376: 108-116.

Sadot, E., Gurwitz, D., Barg, J., Behar, L., Ginzburg, I., and Fisher, A. 1996. Activation of $\mathrm{m} 1$ muscarinic acetylcholine receptor regulates $\tau$ hyperphosphorylation in transfected PC12 cells. J. Neurochem. 66: $877-880$.
Sarter, M. and Bruno, J.P. 2000. Cortical cholinergic inputs mediating arousal, attentional processing and dreaming: Differential afferent regulation of the basal forebrain by telencephalic and brainstem afferents. Neuroscience 95: 933-952.

Sassin, I., Schultz, C., Thal, D.R., Rüb, U., Arai, K., Braak, E., and Braak, H. 2000. Evolution of Alzheimer's disease-related cytoskeletal changes in the basal nucleus of Meynert. Acta Neuropathologica 100: $259-269$.

Smiley, J.F. and Mesulam, M.M. 1999. Cholinergic neurons of the nucleus basalis of Meynert (Ch4) receive cholinergic, catecholaminergic, and GABAergic synapses: An electron microscopic investigation in the monkey. Neuroscience 88: 241-255.

Smiley, J.F., Morrell, F., and Mesulam, M.M. 1997. Cholinergic synapses in human cerebral cortex: An ultrastructural study in serial sections. Exper. Neurol. 144: 361-368.

Summers, W.K., Majorski, L.V., Marsh, G.M., Tachiki, K., and Kling, A. 1986. Oral tetrahydroaminoacridine in long-term treatment of senile dementia, Alzheimer type. New Eng. J. Med. 315: 1241-1245.

Tanaka, Y., Sakurai, M. and Hayashi, S. 1989. Effect of scopolamine and HP029, a cholinesterase inhibitor, on long-term potentiation in hippocampal slices of guinea pig. Neuroscience Letters 98: 179-183.

Thal, L.J., Mandel, R.J., Terry, R.D., Buzsáki, G., and Gage, F.H. 1990. Nucleus basalis lesions fail to induce senile plaques in the rat. Exp. Neurol. 108: 88-90.

Voytko, M.L., Olton, D.S., Richardson, R.T., Gorman, L.K., Tobin, J.R., and Price, D.L. 1994. Basal forebrain lesions in monkeys disrupt attention but not learning and memory. J. Neurosci. 14: 167-186.

Wenk, G.L., Stoehr, J.D., Quintana, G., Mobley, S., and Wiley, R.G. 1994. Behavioral, biochemical, histological, and electrophysiological effects of 192 IgG-saporin injections into the basal forebrain of rats. I. Neurosci. 14: 5986-5995.

Whalen, P.J., Knapp, B.S., and Pascoe, J.P. 1994. Neuronal activity within the nucleus basalis and conditioned neocortical electroencephalographic activation. J. Neurosci. 14: 1623-1633.

Whitehouse, P.J., Price, D.L., Clark, A.W., Coyle, J.T., and DeLong, M.R. 1981. Alzheimer disease: Evidence for selective loss of cholinergic neurons in the nucleus basalis. Ann. Neurol. 10: 122-126.

Wilson, F.A.W. and Rolls, E.T. 1990. Neuronal responses related to novelty and familiarity of visual stimuli in the substantia innominata, diagonal band of Broca and periventricular region of the primate basal forebrain. Exper. Brain Res. 80: 104-120.

Zarow, C., Lyness, S.A., Mortimer, J.A., and Chui, H.C. 2003. Neuronal loss is greater in the locus coeruleus than nucleus basalis and substantia nigra in Alzheimer and Parkinson diseases. Arch. Neurol. 60: $337-341$.

Zhu, X.O. and Waite, P.M.E. 1998. Cholinergic depletion reduces plasticity of barrel field cortex. Cerebral Cortex 8: 63-72. 


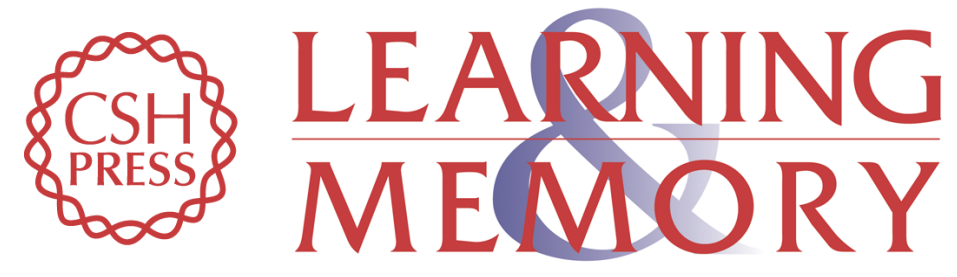

\section{The Cholinergic Lesion of Alzheimer's Disease: Pivotal Factor or Side Show?}

Marsel Mesulam

Learn. Mem. 2004, 11:

Access the most recent version at doi:10.1101/lm.69204

References This article cites 80 articles, 17 of which can be accessed free at: http://learnmem.cshlp.org/content/11/1/43.full.html\#ref-list-1

License

Email Alerting Receive free email alerts when new articles cite this article - sign up in the box at the Service top right corner of the article or click here. 